\title{
Prediction of cardiovascular events in rheumatoid arthritis using risk age calculations: evaluation of concordance across risk age models
}

Grunde Wibetoe ${ }^{1 *}$, Joseph Sexton², Eirik Ikdahl', Silvia Rollefstad', George D. Kitas ${ }^{3,6}$, Piet van Riel ${ }^{4}$, Sherine Gabriel', Tore K. Kvien², Karen Douglas ${ }^{6}$, Aamer Sandoo $^{6,7}$, Elke E. Arts ${ }^{8}$, Solveig Wållberg-Jonsson ${ }^{9}$, Solbritt Rantapää Dahlqvist ${ }^{9}$, George Karpouzas ${ }^{10}$, Patrick H. Dessein ${ }^{11,12}$, Linda Tsang ${ }^{13}$, Hani El-Gabalawy ${ }^{14}$, Carol A. Hitchon ${ }^{14}$, Virginia Pascual-Ramos ${ }^{15}$, Irazu Contreas-Yañes ${ }^{15}$, Petros P. Sfikakis ${ }^{16}$, Miguel A. González-Gay ${ }^{17}$, Iris J. Colunga-Pedraz ${ }^{18}$, Dionicio A. Galarza-Delgado ${ }^{19}$, Jose Ramon Azpiri-Lopez ${ }^{20}$, Cynthia S. Crowson ${ }^{21+}$ and Anne Grete Semb ${ }^{1+}$

\begin{abstract}
Background: In younger individuals, low absolute risk of cardiovascular disease (CVD) may conceal an increased risk age and relative risk of CVD. Calculation of risk age is proposed as an adjuvant to absolute CVD risk estimation in European guidelines. We aimed to compare the discriminative ability of available risk age models in prediction of CVD in rheumatoid arthritis (RA). Secondly, we also evaluated the performance of risk age models in subgroups based on RA disease characteristics.

Methods: RA patients aged 30-70 years were included from an international consortium named A Trans-Atlantic Cardiovascular Consortium for Rheumatoid Arthritis (ATACC-RA). Prior CVD and diabetes mellitus were exclusion criteria. The discriminatory ability of specific risk age models was evaluated using c-statistics and their standard errors after calculating time until fatal or non-fatal CVD or last follow-up.

Results: A total of 1974 patients were included in the main analyses, and 144 events were observed during followup, the median follow-up being 5.0 years. The risk age models gave highly correlated results, demonstrating $R^{2}$ values ranging from 0.87 to 0.97 . However, risk age estimations differed $>5$ years in $15-32 \%$ of patients. C-statistics ranged $0.68-0.72$ with standard errors of approximately 0.03 . Despite certain RA characteristics being associated with low c-indices, standard errors were high. Restricting analysis to European RA patients yielded similar results.
\end{abstract}

Conclusions: The cardiovascular risk age and vascular age models have comparable performance in predicting CVD in RA patients. The influence of RA disease characteristics on the predictive ability of these prediction models remains inconclusive.

Keywords: Cardiovascular risk age, Vascular age, Cardiovascular disease, Risk factors, Rheumatoid arthritis

\footnotetext{
* Correspondence: grunde.wibetoe@diakonsyk.no

Cynthia S. Crowson and Anne Grete Semb shared last authorship.

${ }^{1}$ Preventive Cardio-Rheuma clinic, Department of Rheumatology, Diakonhjemmet Hospital, PO Box 23, Vindern, N-01319 Oslo, Norway

Full list of author information is available at the end of the article
} 


\section{Background}

Patients with rheumatoid arthritis (RA) have higher risk of cardiovascular disease (CVD) [1]. Risk algorithms for the general population lack precision when applied to RA patients, while validated RA-specific CVD prediction models are currently lacking [2-5].

Numerous CVD risk prediction models have been developed and differ in terms of CVD events (fatal or nonfatal), patient population of interest, and also CVD risk factors (CVD-RFs) included [6]. In clinical practice, the decision whether to initiate lipid-lowering therapy or not is supported by calculating the absolute risk of CVD [7]. Using the Systematic Coronary Risk Evaluation (SCORE) algorithm, the absolute 10-year risk of a fatal CVD event can be estimated separately for patients in countries with low and high risk of CVD [8]. The SCORE algorithm estimates CVD risk according to age, sex, and modifiable CVD-RFs including smoking status, systolic blood pressure (sBP), and total cholesterol (TC). Since high-density lipoprotein cholesterol (HDL-c) may improve prediction of CVD, an updated algorithm includes TC to HDL-C ratio $[9,10]$. The European League Against Rheumatism (EULAR) advises to adapt CVD risk prediction models with a 1.5 multiplication factor to the estimated risk of CVD for patients with RA [11].

Absolute risk of CVD the next 10 years is largely driven by age, and younger individuals will thus have a low calculated risk by SCORE, even in the presence of high levels of CVD-RFs [12]. Accordingly, a low absolute 10 -year risk may conceal a high relative and lifetime risk of CVD [7]. Risk age may be a favorable supplement for assessment and communication of CVD risk, and its use is recommended in the guidelines on CVD prevention by the European Society of Cardiology (ESC) in addition to assessment of absolute 10-year risk [7].

The risk age concept estimates the detrimental effects of CVD-RFs, by comparing the absolute risk of the patient of interest to the absolute risk in a hypothetical individual of the same sex with the absence of CVD-RFs (a non-smoker with sBP of $120 \mathrm{mmHg}$ and $\mathrm{TC}$ at $4 \mathrm{mmol} /$ L). Estimated risk age for any given individual may be similar to his/her true age or far beyond the chronologic age in presence of high levels of CVD-RFs. If a 40-yearold has a risk age of 60 years, then he/she has an absolute risk corresponding to a 60 -year-old person of the same sex without CVD-RFs (non-smoker with sBP of $120 \mathrm{mmHg}$ and $\mathrm{TC}$ of $4 \mathrm{mmol} / \mathrm{L}$ ). Currently, two risk age models based on the SCORE algorithm have been developed: the cardiovascular risk age and the vascular age $[13,14]$.

Recently, we reported that different CVD risk age models yield highly correlated results, yet differ by 5 years or more in a substantial fraction of RA patients, suggesting a need for validation of these prediction models [15]. Our objective was to compare the discriminative ability of cardiovascular risk age and vascular age calculations in predicting CVD among RA patients. We also aimed to evaluate the performance of these risk age models in subgroups of RA patients stratified according to rheumatic disease related characteristics.

\section{Methods \\ Study populations}

Patients were included from the international consortium, A Trans-Atlantic Cardiovascular Consortium for Rheumatoid Arthritis (ATACC-RA), which encompasses 11 RA patient cohorts (the UK, Norway, Netherlands, Sweden, Greece, Spain, the USA, South Africa, Canada, Mexico (2 cohorts)) [3]. Approval was granted by the ethical boards/committees at each center. Data were anonymized and aggregated before analyses.

In the current analyses, we included patients aged 3070 years at baseline. Exclusion criteria were prior CVD and/or diabetes mellitus at baseline in line with European guidelines (as CVD risk prediction is limited to patients without known prior CVD and/or diabetes mellitus). For main analyses, we also excluded patients using lipid-lowering therapy (LLT) and/or antihypertensive treatment (AntiHT) at baseline. In secondary analyses, we performed analyses on data from European RA cohorts (subanalyses 1), included RA patients on LLT and/or AntiHT (subanalyses 2), and performed analyses on European RA cohorts also including patients on LLT and/or AntiHT (subanalyses 3).

\section{Demographic and rheumatic disease characteristics}

Age, sex, and RA disease-related variables (disease duration, disease activity score using 28 joint count (DAS28), rheumatoid factor (RF) and anti-citrullinated protein antibodies (ACPA), and treatment with glucocorticoids (GC), synthetic and biologic disease-modifying anti-rheumatic drugs (bDMARDs and sDMARDs)) were collected at baseline. Recorded CVD-RFs included current smoking, sBP, TC, and HDL-c; body mass index (BMI), low-density lipoprotein cholesterol (LDL-c), and triglycerides were also recorded.

\section{Outcomes}

The outcome of interest was time to physician-verified fatal or non-fatal CVD events, including CVD death, myocardial infarction, stroke, peripheral arterial disease (with or without revascularization procedures), and coronary revascularization (percutaneous coronary intervention or coronary artery bypass grafting). Patients were followed from baseline to the time of event or censored at the time of last follow-up. 


\section{Relative risk calculation}

Relative risk of CVD was calculated according to the relative risk chart, which is included in the 2016 European guidelines on CVD prevention in clinical practice, in accordance with smoking status as well as total cholesterol and systolic blood pressure levels [7].

\section{Risk age estimations using the cardiovascular risk age model}

Cardiovascular risk age was estimated according to the cardiovascular risk age chart, based on the nearest intervals of sBP $(120 / 140 / 160 / 180 \mathrm{mmHg})$ and TC (4/5/6/7/ $8 \mathrm{mmol} / \mathrm{L}$ ) for males and females, depending on different chronologic age strata (40/45/50/55/60/65 years) [13].

\section{Risk age estimations using the vascular age model}

In contrast, the vascular age calculation was performed in two steps. First, we estimated 10-year risk of fatal CVD according to the SCORE algorithms $[8,10]$. Then, we matched calculated 10-year risk to corresponding risk ages [14]. The vascular age was calculated in four different ways, corresponding to the four different SCORE formulas for assessing the 10-year risk of fatal CVD: using the formula for low-risk countries and the formula high-risk countries, as well as those with and without HDL-c.

\section{Statistical analysis}

Descriptive data was presented as counts (percentages) for categorical data and as mean or median for normally distributed and non-normally distributed data, respectively. The significance level was set at $p<0.05$.

Since the cardiovascular risk age model was developed for patients aged $40-65$, ages $30-40$ and $65-70$ years were truncated to 40 and 65 years, respectively. Agreement between risk age models was evaluated using $R^{2}$ from a linear regression model and the frequency of risk age estimations differing 5 years or more across models.

To validate the CVD risk prediction models, discrimination (e.g., correctly ranking patients who experience CVD as individuals at higher risk than those who do not experience CVD) was calculated using concordance statistics (c-statistics) [16, 17]. Moreover, c-statistics with standard errors were compared across risk age models to evaluate which risk age models perform better at ranking individuals correctly as low- or high-risk individuals (in which the latter should have shorter observed time to event). Concordance was also estimated for individual centers.

Furthermore, concordance according to sex and baseline RA disease characteristics was calculated to assess whether these features influence the risk age model's predictive ability. In detail, these RA disease characteristics included (1) disease duration $\leq 1$ vs. $>1$ year, (2) disease activity (remission/low disease activity vs. moderate/high disease activity according to DAS28) [18, 19], (3) seropositivity (RF and/or ACPA positivity), and presence or absence of anti-rheumatic treatment with (4) glucocorticoids, (5) methotrexate, (6) sDMARDs in general, or (7) bDMARDs. The sampling variability of these sub-group c-statistics was assessed using standard errors.

Statistical analyses were conducted using R 3.2.0 ( $\mathrm{R}$ Foundation for Statistical Computing, Vienna, Austria) and STATA version 14.1.

\section{Results}

Table 1 presents baseline characteristics of the 1973 RA patients included in the main analyses.

Seventy-four percent were female, and median (interquartile range) age was $52.0(44,59)$ years. Disease duration was $0.6(0.1,5.8)$ years, and more than half $(61 \%)$ had an RA disease duration of 1 year or less. Overall, $73 \%$ were RF positive. There were a substantial number of patients with moderate $(43 \%)$ or high $(30 \%)$ disease activity according to DAS28. Twenty-four percent were treated with glucocorticoids, while $10 \%$ and $38 \%$ were using bDMARDs and sDMARDs, respectively. About a third (30\%) were current smokers, and 19\% were obese $\left(\mathrm{BMI} \geq 30 \mathrm{~kg} / \mathrm{m}^{2}\right)$.

The median follow-up time was $5.0(2.5,9.1)$ years. A total of 144 RA patients experienced CVD events during the observation period: confirmed myocardial infarction $(n=64)$, stroke $(n=33)$, CVD death $(n=19)$, peripheral arterial events $(n=14)$, and revascularization procedures $(n=14)$. Among the patients included in the main analyses, estimation of risk age was not possible in 338 (17\%) and $357(18 \%)$ individuals when using prediction models without or with HDL-c, respectively, due to missing data on $\operatorname{sBP}(n=114)$, TC $(n=205)$, HDL-c $(n=$ $219)$, and current smoking $(n=119)$.

The estimated risk of CVD according to different prediction models are presented in Table 2. Calculated risk age was highest when the cardiovascular risk age model was applied and, depending on the specific risk age model used, the median risk age ranged from 56 to 59 years. According to the relative risk table, two thirds of patients with RA had at least twice the risk of CVD (due to either smoking and/or elevated sBP/TC levels), compared to individuals with no CVD-RFs, whereas 7-28\% of RA patients would be classified as high-risk individuals (absolute 10-year risk of fatal CVD $\geq 5 \%$ ) at baseline, depending on which SCORE algorithm was used and if the EULAR 1.5 multiplication factor was applied or not.

The scatter plot (Fig. 1) gives a graphical presentation of the agreement between estimated risk age according to the cardiovascular risk age model and the various 
Table 1 Patient characteristics

\begin{tabular}{|c|c|c|c|c|}
\hline & Main population $(\boldsymbol{n}=1974)$ & Sub-analyses $1(\boldsymbol{n}=1543)$ & Sub-analyses $2(\boldsymbol{n}=2617)$ & Sub-analyses $3(\boldsymbol{n}=1991)$ \\
\hline Follow-up time in years, median (IQR) & $5(2.6,9.1)$ & $5(2.7,10.3)$ & $5(2.3,7.7)$ & $5(2.5,8.5)$ \\
\hline Age in years, median (IQR) & $52.0(43.7,59.4)$ & $53.1(45,60.5)$ & $54(45.5,61)$ & $55.3(46.8,62)$ \\
\hline Females, $n(\%)$ & $1465(74 \%)$ & $1095(71 \%)$ & $1955(75 \%)$ & $1432(72 \%)$ \\
\hline $\begin{array}{l}\text { Disease duration in years, median } \\
\text { (IQR) }\end{array}$ & $0.6(0.1,5.8)$ & $0.4(0,4.3)$ & $0.8(0.1,7.6)$ & $0.6(0.1,6)$ \\
\hline Rheumatoid factor, $n$ (\%) & $1437(73 \%)$ & $1078(70 \%)$ & 1907 (74\%) & $1392(70 \%)$ \\
\hline $\begin{array}{l}\text { Anti-cyclic citrullinated peptide } \\
\text { antibody, } n(\%)\end{array}$ & $1239(66 \%)$ & $905(62 \%)$ & $1649(67 \%)$ & $1177(63 \%)$ \\
\hline Glucocorticosteroids, $n$ (\%) & 469 (24\%) & $345(22 \%)$ & $675(26 \%)$ & $502(25 \%)$ \\
\hline Biologic DMARD, $n$ (\%) & $193(10 \%)$ & $149(10 \%)$ & $321(12 \%)$ & $239(12 \%)$ \\
\hline Synthetic DMARD, n (\%) & $722(38 \%)$ & $517(34 \%)$ & $1056(43 \%)$ & $743(37 \%)$ \\
\hline Methotrexate, $n(\%)$ & $581(30 \%)$ & $365(24 \%)$ & $864(34 \%)$ & $529(27 \%)$ \\
\hline DAS 28, mean (SD) & $4.2(1.6)$ & $4.3(1.5)$ & $4.1(1.6)$ & $4.2(1.5)$ \\
\hline Remission $(<2.6)$ & $334(18 \%)$ & $206(14 \%)$ & $491(20 \%)$ & $280(15 \%)$ \\
\hline Low disease activity $(2.6,3.2)$ & $169(9 \%)$ & $141(10 \%)$ & $234(9 \%)$ & $187(10 \%)$ \\
\hline Moderate disease activity $(3.2,5.1)$ & $810(43 \%)$ & $681(47 \%)$ & $1051(42 \%)$ & $876(47 \%)$ \\
\hline High disease activity (> 5.1) & $566(30 \%)$ & $433(30 \%)$ & $704(28 \%)$ & $540(29 \%)$ \\
\hline CRP (mg/l), median (IQR) & $6.2(1.4,18)$ & $8(2,21)$ & $6.2(1.4,17)$ & $8(2,20)$ \\
\hline ESR (mm/h), median (IQR) & $20(10,35.9)$ & $20(10,36)$ & $20(10,36)$ & $20(10,36)$ \\
\hline TJC 28, median (IQR) & $4(1,8)$ & $4(2,8)$ & $4(1,8)$ & $4(1,8)$ \\
\hline SJC 28, median (IQR) & $5(2,9)$ & $5(2,9)$ & $4(1,9)$ & $5(2,9)$ \\
\hline $\begin{array}{l}\text { Total cholesterol }(\mathrm{mmol} / \mathrm{l}) \text {, median } \\
\text { (IQR) }\end{array}$ & $5.2(4.4,5.9)$ & $5.3(4.5,6.1)$ & $5.2(4.4,6)$ & $5.4(4.6,6.1)$ \\
\hline HDL-c (mmol/l), median (IQR) & $1.4(1.1,1.7)$ & $1.4(1.2,1.7)$ & $1.4(1.1,1.7)$ & $1.4(1.2,1.7)$ \\
\hline LDL-c (mmol/l), median (IQR) & $3.1(2.4,3.8)$ & $3.2(2.6,4)$ & $3.1(2.4,3.8)$ & $3.2(2.6,3.9)$ \\
\hline Triglyceride (mmol/l), median (IQR) & $1.2(0.9,1.7)$ & $1.2(0.9,1.7)$ & $1.2(0.9,1.7)$ & $1.2(0.9,1.7)$ \\
\hline Systolic BP (mm Hg), mean (SD) & $134.1(21.4)$ & $137.7(21.2)$ & $136.1(21.8)$ & $139.7(21.7)$ \\
\hline Diastolic BP (mm Hg), mean (SD) & $80.1(10.8)$ & $81.4(10.5)$ & $80.8(11)$ & $82.2(10.7)$ \\
\hline BMI $\left(\mathrm{kg} / \mathrm{m}^{2}\right)$, median (IQR) & $25.6(23.0,28.7)$ & $25.4(22.9,28.4)$ & $26.1(23.4,29.5)$ & $25.9(23.3,29.3)$ \\
\hline $\mathrm{BMI} \geq 30 \mathrm{~kg} / \mathrm{m}^{2}, n(\%)$ & $324(19 \%)$ & 226 (17\%) & $523(23 \%)$ & $366(22 \%)$ \\
\hline Current smokers, $n$ (\%) & $560(30 \%)$ & 497 (34\%) & $678(28 \%)$ & 599 (32\%) \\
\hline
\end{tabular}

$I Q R$ inter-quartile range, $S D$ standard deviation, $b D M A R D s$ and $s D M A R D$ s biologic and synthetic disease-modifying antirheumatic drugs, $D A S 28$ disease activity score using 28 joint count, CRP C-reactive protein, ESR erythrocyte sedimentation rate, $H D L$-c high-density lipoprotein cholesterol, $s B P$ and $d B P$ systolic and diastolic blood pressure. Baseline characteristics describing demographic data, rheumatoid arthritis-related disease characteristics, and cardiovascular risk factors in rheumatoid arthritis at baseline. Data are also specified on patients who do and do not experience CVD events during follow-up. In subanalyses 1 , only European rheumatoid arthritis cohorts were included. In subanalyses 2, rheumatoid arthritis patients on lipid-lowering therapy and/or antihypertensive treatment were included. In subanalyses 3, analyses were performed on patients from European rheumatoid arthritis cohorts also including patients on lipid-lowering therapy and/or antihypertensive treatment

vascular age models. Linear regression analyses, calculating the correlation between the risk age models, yielded $R^{2}$ values ranging from 0.87 to 0.97 . Moreover, comparison of cardiovascular risk age and various vascular age models revealed that risk age estimations differed $\geq 5$ years in $15-32 \%$ of observations. The most extreme risk age difference was 21 years in which a female non-smoker, aged 69 years, sBP of $151 \mathrm{mmHg}$ and HDL-c and TC of 2.8 and $7.5 \mathrm{mmol} / \mathrm{L}$, respectively, had a cardiovascular risk age of 80 years, and a vascular age of 59 according to the vascular age model (using the SCORE HDL-c algorithm for low-risk countries).
Overall, the risk age algorithms had c-indices ranging from 0.68 to 0.72 , with standard errors (SE) around 0.03 (Table 3). The cardiovascular risk age model had the lowest c-index. Applying the EULAR 1.5 multiplication factor to the estimated risk do not change the risk ranking of subjects and thereby have no impact on concordance. Table 3 also presents the c-indexes when stratifying on sex and RA disease related characteristics. Certain characteristics were associated with low concordance, but standard errors were high. Additional analyses restricted to only European cohorts and/or 
Table 2 Estimated risk age, relative risk, and absolute risk

\begin{tabular}{|c|c|}
\hline Risk age & All patients \\
\hline Cardiovascular risk age in years, median (IQR) & $59(48,69)$ \\
\hline Vascular age in years, median (IQR)[SCORE-Hrisk algorithm] & $57(46,67)$ \\
\hline Vascular age in years, median (IQR)[SCORE-Lrisk algorithm] & $56(45,66)$ \\
\hline Vascular age in years, median (IQR)[SCORE-HDL-c-Hrisk algorithm] & $58(49,67)$ \\
\hline Vascular age in years, median (IQR)[SCORE-HDL-c-Lrisk algorithm] & $56(47,65)$ \\
\hline \multicolumn{2}{|l|}{ Relative risk } \\
\hline Relative risk of $1, n(\%)$ & $562(34.4)$ \\
\hline Relative risk of $2, n(\%)$ & $473(28.9)$ \\
\hline Relative risk of $3, n(\%)$ & $316(19.3)$ \\
\hline Relative risk of $4, n(\%)$ & $124(7.6)$ \\
\hline Relative risk of $5, n(\%)$ & $60(3.7)$ \\
\hline Relative risk of $6, n(\%)$ & $50(3.1)$ \\
\hline Relative risk of $7, n(\%)$ & $32(2.0)$ \\
\hline Relative risk of $8, n(\%)$ & $10(0.6)$ \\
\hline Relative risk of $10, n$ (\%) & $7(0.4)$ \\
\hline Relative risk of $12, n(\%)$ & $2(0.1)$ \\
\hline \multicolumn{2}{|l|}{ Individuals with an absolute 10 -year risk of fatal CVD $\geq 5 \%$} \\
\hline SCORE-Hrisk algorithm, $n$ (\%) & $295(18.0)$ \\
\hline SCORE-Lrisk algorithm, $n$ (\%) & $131(8.0)$ \\
\hline SCORE-HDLc-Hrisk algorithm, $n$ (\%) & 305 (18.9) \\
\hline SCORE-HDLc-Lrisk algorithm, $n$ (\%) & $111(6.9)$ \\
\hline mSCORE-Hrisk algorithm, $n$ (\%) & $447(27.3)$ \\
\hline mSCORE-Lrisk algorithm, $n$ (\%) & $248(15.2)$ \\
\hline mSCORE-HDLc-Hrisk algorithm, n (\%) & $461(28.2)$ \\
\hline mSCORE-HDLc-Lrisk algorithm, $n$ (\%) & $235(14.4)$ \\
\hline
\end{tabular}

including patients on LLT and/or AntiHT gave comparable results (data not shown). Finally, we evaluated the concordance of risk models for each center, which revealed wide ranging $\mathrm{c}$-indexes (data not shown). For centers in which CVD events did not occur during the observation period, concordance could not be calculated (data not shown).

\section{Discussion}

Using longitudinal data with CVD outcomes from rheumatic outpatient clinics from the total ATACC-RA cohort, we have revealed comparable ability of various risk age models to rank RA patients in terms of time to CVD events. Interestingly, the cardiovascular risk age chart, which is based on quite wide CVD-RF intervals (e.g., sBP 120/140/160/180 mmHg), had only a slightly lower c-index (0.68) than the other risk age models, indicating comparable performance in correct ranking of individuals in terms of future CVD risk. Thus, although risk age estimations frequently differ 5 years or more [15], their discriminative ability is very similar.

Among the included RA patients, the concordance was about 0.7 for all risk age models and similar to the SCORE algorithms they are based on, which had a cindex of $0.71-0.72$. Thus, c-indices were somewhat lower than what was reported for the general European population in the original SCORE paper. Conroy et al. found c-indices of 0.81 and 0.74 for high- and low-risk countries, respectively [8].

Evaluating risk age models by investigating time to event and using a composite of CVD events, the cardiovascular risk age model and the vascular age models all had comparable c-statistics around 0.7. In comparison, a concordance of 0.5 implies a discriminative ability no better than pure chance, whereas c-statistics approaching 0.60 to 0.75 are sometimes expressed as 


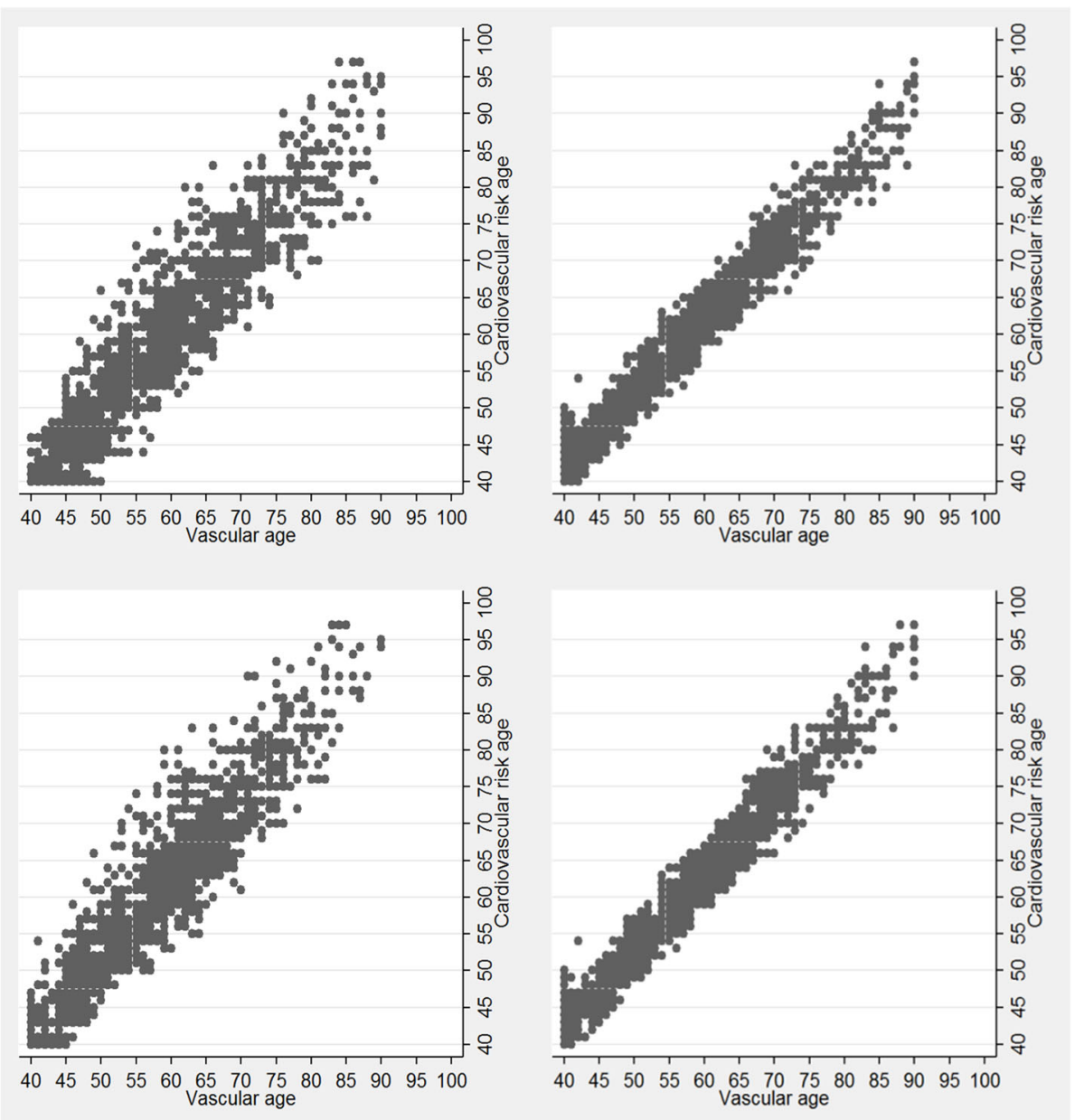

Fig. 1 Agreement in estimated risk age by the cardiovascular risk age and vascular age models. Cardiovascular risk age estimations versus cardiovascular risk age calculations using the SCORE algorithms with (left panels) or without HDL-C (right panels) for high-risk countries (top panels) and low-risk countries (bottom panels)

demonstration of "possibly helpful discrimination" and $>0.75$ as "clearly useful discrimination" (although this is a criticized practice) [20].

External validation of the SCORE algorithm, from which the cardiovascular risk age and vascular age models are based on and calculated from, respectively, have revealed wide ranging $\mathrm{c}$-statistics. In a review by Damen et al., reported c-indices ranged from 0.62 to 0.91 in different European and non-European study populations [6]. Comparisons of c-indices across populations are hampered due to factors such as differences in age distributions. However, for analyses in these cohorts, several additional explanations of the observed suboptimal concordance are plausible. The SCORE algorithm was developed for the European population. In our analyses, European and non-European cohorts were included. Additional analyses restricted to data from European cohorts were performed, but comparable cindices were found. We also performed CVD risk estimations using both algorithms for high- and low-risk countries. In the main analyses, we pooled data across centers to increase the numbers and observation time (total person years at risk), but a limitation is the heterogeneity between the various cohorts. There was wide range of the c-indexes and standard errors across each unique center included in the analyses.

In RA, inflammatory disease activity, disease duration, and usage of GCs, sDMARDs, and bDMARDs are all factors that may influence overall risk of CVD [21-28]. In a recent study, Crowson et al. demonstrated that albeit conventional CVD-RFs accounted for half $(49 \%)$ of CVD events in RA, high-grade inflammation and RA characteristics explained about $30 \%$ of the CVD risk [29]. However, the prediction models we evaluated only assess CVD risk related to conventional CVD-RFs. Furthermore, RA patients without known CVD have high occurrence of atherosclerotic plaques even in the case of only moderate estimated absolute risk, justifying the use 
Table 3 Discriminatory ability according to stratification by RA disease characteristics

\begin{tabular}{|c|c|c|c|c|c|c|c|c|c|c|c|c|}
\hline & \multicolumn{4}{|c|}{ Sex } & \multicolumn{2}{|l|}{ RF } & \multicolumn{2}{|l|}{ ACPA } & \multicolumn{2}{|l|}{ ACPA/RF } & \multicolumn{2}{|c|}{ bDMARDs } \\
\hline & All & Male & \multicolumn{2}{|c|}{ Female } & Positive & Negative & Positive & Negative & Positive & Negative & Use & No use \\
\hline $\begin{array}{l}\text { Cardiovascular risk } \\
\text { age }\end{array}$ & $\begin{array}{l}0.68 \\
(0.03)\end{array}$ & $\begin{array}{l}0.7 \\
(0.05)\end{array}$ & \multicolumn{2}{|c|}{$0.63(0.05)$} & $\begin{array}{l}0.68 \\
(0.04)\end{array}$ & $\begin{array}{l}0.68 \\
(0.08)\end{array}$ & $\begin{array}{l}0.72 \\
(0.04)\end{array}$ & $\begin{array}{l}0.61 \\
(0.06)\end{array}$ & $\begin{array}{l}0.71 \\
(0.04)\end{array}$ & $0.65(0.1)$ & $\begin{array}{l}0.78 \\
(0.14)\end{array}$ & $\begin{array}{l}0.67 \\
(0.03)\end{array}$ \\
\hline Vascular age $[\mathrm{H}$-risk] & $\begin{array}{l}0.71 \\
(0.03)\end{array}$ & $\begin{array}{l}0.72 \\
(0.05)\end{array}$ & \multicolumn{2}{|c|}{$0.67(0.04)$} & $\begin{array}{l}0.7 \\
(0.04)\end{array}$ & $\begin{array}{l}0.77 \\
(0.07)\end{array}$ & $\begin{array}{l}0.74 \\
(0.04)\end{array}$ & $\begin{array}{l}0.67 \\
(0.06)\end{array}$ & $\begin{array}{l}0.74 \\
(0.04)\end{array}$ & $\begin{array}{l}0.75 \\
(0.08)\end{array}$ & $\begin{array}{l}0.78 \\
(0.14)\end{array}$ & $\begin{array}{l}0.71 \\
(0.03)\end{array}$ \\
\hline Vascular age [L-risk] & $\begin{array}{l}0.71 \\
(0.03)\end{array}$ & $\begin{array}{l}0.72 \\
(0.05)\end{array}$ & \multicolumn{2}{|c|}{$0.67(0.04)$} & $\begin{array}{l}0.7 \\
(0.04)\end{array}$ & $\begin{array}{l}0.76 \\
(0.07)\end{array}$ & $\begin{array}{l}0.74 \\
(0.04)\end{array}$ & $\begin{array}{l}0.67 \\
(0.06)\end{array}$ & $\begin{array}{l}0.73 \\
(0.04)\end{array}$ & $\begin{array}{l}0.74 \\
(0.08)\end{array}$ & $0.8(0.14)$ & $\begin{array}{l}0.71 \\
(0.03)\end{array}$ \\
\hline $\begin{array}{l}\text { Vascular age }[H D L C \\
\text { H-risk }\end{array}$ & $\begin{array}{l}0.71 \\
(0.03)\end{array}$ & $\begin{array}{l}0.71 \\
(0.05)\end{array}$ & \multicolumn{2}{|c|}{$0.68(0.04)$} & $\begin{array}{l}0.7 \\
(0.03)\end{array}$ & $\begin{array}{l}0.78 \\
(0.07)\end{array}$ & $\begin{array}{l}0.73 \\
(0.04)\end{array}$ & $\begin{array}{l}0.69 \\
(0.06)\end{array}$ & $\begin{array}{l}0.72 \\
(0.04)\end{array}$ & $\begin{array}{l}0.77 \\
(0.08)\end{array}$ & $\begin{array}{l}0.78 \\
(0.14)\end{array}$ & $\begin{array}{l}0.71 \\
(0.03)\end{array}$ \\
\hline \multirow[t]{3}{*}{$\begin{array}{l}\text { Vascular age [HDLC } \\
\text { L-risk] }\end{array}$} & $\begin{array}{l}0.72 \\
(0.03)\end{array}$ & $\begin{array}{l}0.72 \\
(0.05)\end{array}$ & \multicolumn{2}{|c|}{$0.68(0.04)$} & $\begin{array}{l}0.7 \\
(0.03)\end{array}$ & $\begin{array}{l}0.76 \\
(0.07)\end{array}$ & $\begin{array}{l}0.74 \\
(0.04)\end{array}$ & $\begin{array}{l}0.69 \\
(0.06)\end{array}$ & $\begin{array}{l}0.73 \\
(0.04)\end{array}$ & $\begin{array}{l}0.75 \\
(0.08)\end{array}$ & $\begin{array}{l}0.79 \\
(0.14)\end{array}$ & $\begin{array}{l}0.71 \\
(0.03)\end{array}$ \\
\hline & \multicolumn{2}{|c|}{ Glucocorticoids } & \multicolumn{2}{|c|}{ DAS28 } & \multicolumn{3}{|c|}{ RA disease duration } & \multicolumn{3}{|c|}{ Methotrexate } & \multicolumn{2}{|c|}{ sDMARDs } \\
\hline & Use & No use & $<3.2$ & $\geq 3.2$ & $\leq 1$ year & \multicolumn{2}{|l|}{$>1$ year } & Use & \multicolumn{2}{|l|}{ No use } & Use & No use \\
\hline $\begin{array}{l}\text { Cardiovascular risk } \\
\text { age }\end{array}$ & $\begin{array}{l}0.57 \\
(0.08)\end{array}$ & $\begin{array}{l}0.71 \\
(0.04)\end{array}$ & $\begin{array}{l}0.6 \\
(0.09)\end{array}$ & $\begin{array}{l}0.69 \\
(0.04)\end{array}$ & $\begin{array}{l}0.69 \\
(0.03)\end{array}$ & \multicolumn{2}{|l|}{$0.6(0.08)$} & $\begin{array}{l}0.67 \\
(0.09)\end{array}$ & \multicolumn{2}{|l|}{$0.68(0.03)$} & $\begin{array}{l}0.62 \\
(0.08)\end{array}$ & $\begin{array}{l}0.69 \\
(0.03)\end{array}$ \\
\hline Vascular age $[H$-risk] & $\begin{array}{l}0.61 \\
(0.08)\end{array}$ & $\begin{array}{l}0.74 \\
(0.03)\end{array}$ & $\begin{array}{l}0.67 \\
(0.09)\end{array}$ & $\begin{array}{l}0.72 \\
(0.03)\end{array}$ & $\begin{array}{l}0.73 \\
(0.03)\end{array}$ & \multicolumn{2}{|l|}{$0.63(0.08)$} & $\begin{array}{l}0.68 \\
(0.09)\end{array}$ & \multicolumn{2}{|l|}{$0.72(0.03)$} & $\begin{array}{l}0.64 \\
(0.08)\end{array}$ & $\begin{array}{l}0.73 \\
(0.03)\end{array}$ \\
\hline Vascular age [L-risk] & $\begin{array}{l}0.59 \\
(0.08)\end{array}$ & $\begin{array}{l}0.74 \\
(0.03)\end{array}$ & $\begin{array}{l}0.67 \\
(0.09)\end{array}$ & $\begin{array}{l}0.71 \\
(0.03)\end{array}$ & $\begin{array}{l}0.73 \\
(0.03)\end{array}$ & \multicolumn{2}{|l|}{$0.63(0.08)$} & $0.7(0.09)$ & \multicolumn{2}{|l|}{$0.71(0.03)$} & $\begin{array}{l}0.65 \\
(0.08)\end{array}$ & $\begin{array}{l}0.72 \\
(0.03)\end{array}$ \\
\hline $\begin{array}{l}\text { Vascular age }[\mathrm{HDLC} \\
\text { H-risk }\end{array}$ & $\begin{array}{l}0.6 \\
(0.08)\end{array}$ & $\begin{array}{l}0.74 \\
(0.03)\end{array}$ & $\begin{array}{l}0.66 \\
(0.09)\end{array}$ & $\begin{array}{l}0.72 \\
(0.03)\end{array}$ & $\begin{array}{l}0.73 \\
(0.03)\end{array}$ & \multicolumn{2}{|l|}{$0.63(0.08)$} & $\begin{array}{l}0.69 \\
(0.09)\end{array}$ & \multicolumn{2}{|l|}{$0.72(0.03)$} & $\begin{array}{l}0.65 \\
(0.08)\end{array}$ & $\begin{array}{l}0.72 \\
(0.03)\end{array}$ \\
\hline $\begin{array}{l}\text { Vascular age [HDLC } \\
\text { Lrisk] }\end{array}$ & $\begin{array}{l}0.62 \\
(0.08)\end{array}$ & $\begin{array}{l}0.74 \\
(0.03)\end{array}$ & $\begin{array}{l}0.67 \\
(0.09)\end{array}$ & $\begin{array}{l}0.72 \\
(0.03)\end{array}$ & $\begin{array}{l}0.73 \\
(0.03)\end{array}$ & \multicolumn{2}{|l|}{$0.64(0.08)$} & $\begin{array}{l}0.71 \\
(0.09)\end{array}$ & \multicolumn{2}{|l|}{$0.72(0.03)$} & $\begin{array}{l}0.66 \\
(0.08)\end{array}$ & $\begin{array}{l}0.72 \\
(0.03)\end{array}$ \\
\hline
\end{tabular}

Concordance index (standard error) presenting the discriminative ability in ranking individuals who do or do not experience cardiovascular events correctly as high and low risk. Values are presented for various risk age models, including vascular age estimations derived from application of different Systematic Coronary Risk Evaluation algorithms with or without use of high-density lipoprotein-cholesterol (HDLc) for high- and low-risk countries (H-risk and L-risk). Individuals were also stratified according to sex, rheumatoid factor (RF), and anti-cyclic citrullinated peptide antibody (ACPA) positivity, use of biologic or synthetic disease modifying antirheumatic drugs (bDMARDs and sDMARDs), disease activity score using 28-joint count (DAS28), and duration of rheumatoid arthritis (RA) Significance and innovations

- Risk age estimations have been advocated in current guidelines for CVD prevention

- The two proposed risk age models have not been validated

- Our results indicate comparable performance of risk age models in rheumatoid arthritis patients

of carotid ultrasound as a supplement in CVD risk stratification [30].

The latest EULAR recommendations on CVD risk management underline that rheumatic disease activity should be controlled to lower overall risk of CVD [11]. RArelated characteristics may also complicate the interpretation of conventional CVD-RFs. The lipid paradox denotes the phenomena in which low lipid levels due to elevated inflammation is associated with an increased risk of CVD [31]. Thus, a future RA-specific CVD risk algorithm should possibly weight lipid levels according to the disease activity. Regarding CVD prediction models, if important CVD-RFs are left out or not weighted appropriately, then concordance will be impaired.

In this paper, we aimed to evaluate the influence of RA disease characteristics on the performance of risk age models in ranking individuals correctly as high(er)or low(er)-risk individuals. However, our findings were inconclusive due to the lack of statistical power resulting from the small number of participants included and/or short observation time with few events occurring.
Underreporting of CVD events during the follow-up time is also possible, especially since RA patients may suffer from asymptomatic CVD events [32]. The inconclusive results on the association of RA disease characteristics and the c-index values due to large standard errors could have been different with a longer follow-up time and more participants. In time-to-event analyses, consideration of informative and interval censoring is also required. Only data on disease activity and sDMARD and bDMARD treatment were available at baseline. Surprisingly, a high rate of RA patients was not using sDMARDs and bDMARDs at study inclusion. Although this should be considered before extrapolation of our results to other RA cohorts, this may be partly explained by that a high rate of RA patients included in these analyses had short disease duration (explaining why some were methotrexate naive) and also to differences across different nations (explaining why some were bDMARDs naïve). Another limitation to this multi-center study is the lack to control that BP measurements were conducted similarly. Data on family 
history of premature CVD were also lacking. Among eligible patients, estimation of risk age were not possible in 338-357 individuals when using prediction models without or with HDL-c, respectively, due to missing data on sBP $(n=114)$, TC $(n=205)$, HDL-c $(n=219)$, and current smoking $(n=119)$.

There are also limitations with c-index calculation since it reports concordance based on ranks and not on the magnitude of risk differences. Consequently, in the case of very similar and only slightly different risk ages across subjects, the CVD prediction model's discriminatory ability will be impaired. Moreover, concordance only describes one feature regarding the predictive ability of a risk model. Calibration, a comparison of the number of expected events to the number of observed events, is another important property regarding validation of prediction models [33]. However, in contrast to models predicting absolute risk, calibration cannot be performed in prediction models using the risk age concept.

The risk age models we have validated are derived from the SCORE algorithms which calculate absolute risk of fatal CVD. In the original SCORE publication, the authors argued that developing a CVD prediction model based on non-fatal CVD events are prone to errors due to misclassification. Non-fatal events are also of clinical importance, and it has been suggested to convert SCORE with a multiplier to estimate fatal and non-fatal events [7, 34]. However, Jørstad et al. found that the ratio of risk of fatal to fatal plus non-fatal CVD was largely dependent on age and sex and, consequently, a fixed multiplication factor was not applicable [35]. Since risk age communicates the detrimental effects of modifiable CVD-RFs on overall CVD risk and/or life expectancy, it is an attractive concept, also informing patients on the benefit of optimizing CVD-RFs. In the review by Groenewegen et al., it is argued that the perspicuous risk age concept might improve communication about CVD risk and possibly patient adherence to CVD preventive strategies (e.g. lifestyle changes and/or cardio-protective medication) [12]. CVD risk assessment is especially important in RA due to the high prevalence of modifiable CVD-RFs [3638]. However, whether the risk age is an intuitive concept and if it has incremental value beyond absolute and relative risk calculation needs further evaluation.

To our knowledge, this is the first study comparing the discriminative ability of the risk age models proposed for use as supplements to CVD risk evaluation in the ESC guidelines for the general population [7, 12]. Not surprisingly, our study supports the notion that risk age models perform similarly to the SCORE algorithms in ranking individuals correctly as high or low risk of CVD events. Despite that risk age estimations frequently differ 5 years or more, the current risk age models based on SCORE perform almost equivalently in terms of concordance.

\section{Conclusions}

Albeit different CVD risk age algorithms yield marked disparities in a substantial proportion of patients, the cardiovascular risk age and vascular age models have comparable performance in predicting CVD events in RA patients. Furthermore, their concordance is equivalent to the SCORE algorithms they are derived from. The influence of RA disease characteristics on the predictive ability of these prediction models remains inconclusive. Further evaluation is also required to assess whether use of risk age estimations in clinical practice is beneficial for CVD-RF reduction and, ultimately, prevention of CVD events.

\section{Abbreviations}

ACPA: Anti-citrullinated protein antibodies; AntiHT: Antihypertensive treatment; ATACC-RA: A Trans-Atlantic Cardiovascular Consortium for Rheumatoid Arthritis; bDMARDs: Biologic disease-modifying anti-rheumatic drugs; BMI: Body mass index; CVD: Cardiovascular disease; CVD-RFs: CVD risk factors; C-statistics: Concordance statistics; EULAR: European League Against Rheumatism; ESC: European Society of Cardiology; GC: Glucocorticoids; HDLc: High-density lipoprotein cholesterol; LLT: Lipid-lowering therapy; LDLc: Low-density lipoprotein cholesterol; RA: Rheumatoid arthritis; RF: Rheumatoid factor; SE: Standard errors; sDMARDs: Synthetic diseasemodifying anti-rheumatic drugs; SCORE: Systematic Coronary Risk Evaluation; sBP: Systolic blood pressure; TC: Total cholesterol

\section{Acknowledgements \\ We wish to acknowledge the contribution of all patients and involved health personnel. We also wish to acknowledge these additional members of ATACC-RA: Evangelia Zampeli, Alfonso Corrales, Elaine Husni, Ellen Romich, Torkell Ellingsen, Dzenan Masic, Mette Herly, John J. Carey, and Miriam O'Sullivan.}

\section{Authors' contributions}

GW, JS, and CSC performed the statistics. GW, JS, CSC, El, SR, CSC, and AGS analyzed and interpreted the data. GW drafted the manuscript while all authors revised and approved the final manuscript.

\section{Funding}

This work was supported by a collaborative agreement for independent research from Eli Lilly and grants from the Norwegian South East Health Authority (grant numbers 2013064, 2013010). Funding bodies had no role in the design of the study or the collection, analysis, or interpretation of data, nor in the writing of the manuscript.

\section{Availability of data and materials}

The dataset used and/or analyzed during the current study are available from the corresponding author on reasonable request.

\section{Ethics approval and consent to participate}

Approval was granted by the ethical boards/committees at each center. Data were anonymized and aggregated before the analyses.

\section{Consent for publication}

Not applicable

\section{Competing interests}

The authors declare that they have no competing interests.

\section{Author details}

${ }^{1}$ Preventive Cardio-Rheuma clinic, Department of Rheumatology,

Diakonhjemmet Hospital, PO Box 23, Vindern, N-01319 Oslo, Norway. 
${ }^{2}$ Department of Rheumatology, Diakonhjemmet Hospital, Oslo, Norway. ${ }^{3}$ School of Sport, Exercise and Rehabilitation, University of Birmingham, Birmingham, UK. ${ }^{4}$ Radboud Institute for Health Sciences, IQ healthcare, Radboud University Medical Center, Nijmegen, The Netherlands. ${ }^{5}$ Rutgers Robert Wood Johnson Medical School, New Brunswick, NJ, USA. ${ }^{6}$ Dudley Group NHS Foundation Trust, West Midlands, UK. ${ }^{7}$ School of Sport, Health and Exercise Sciences, Bangor University, Bangor, UK. ${ }^{8}$ Department of Rheumatic Diseases, Radboud University Nijmegen Medical Centre, Nijmegen, Netherlands. ${ }^{9}$ Department of Public Health and Clinical Medicine, Rheumatology, Umeå University, Umeå, Sweden. ${ }^{10}$ Division of Rheumatology, Harbor-UCLA Medical Center, Torrance, CA, USA. ${ }^{11}$ Vrije Universiteit Brussel, Brussels, Belgium. ${ }^{12}$ Universitair Ziekenhuis Brussel, Brussels, Belgium.

${ }^{13}$ Rheumatology, Universitair Ziekenhuis Brussel, Brussels, Belgium.

${ }^{14}$ University of Manitoba, Winnipeg, MB, Canada. ${ }^{15}$ Instituto Nactional de Ciencias Médicas y Nutrición Salvador Zubirán, México City, Mexico. ${ }^{16}$ First Department of Propedeutic Internal Medicine, National and Kapodistrian University of Athens, Athens, Greece. ${ }^{17}$ Rheumatology, Hospital Universitario Marqués de Valdecilla, IDIVAL, Universidad de Cantabria, Santander, Spain. ${ }^{18}$ Rheumatology, Hospital Universitario, UANL, Monterrey, Mexico. ${ }^{19}$ Hospital Universitario, UANL, Monterrey, Mexico. ${ }^{20}$ Cardiology, Hospital Universitario, UANL, Monterrey, Mexico. ${ }^{21}$ Division of Rheumatology, Department of Medicine, Mayo Clinic, Rochester, MN, USA.

Received: 14 November 2019 Accepted: 31 March 2020 Published online: 23 April 2020

\section{References}

1. Avina-Zubieta JA, Thomas J, Sadatsafavi M, et al. Risk of incident cardiovascular events in patients with rheumatoid arthritis: a meta-analysis of observational studies. Ann Rheum Dis. 2012;71(9):1524-9.

2. Crowson CS, Matteson EL, Roger VL, et al. Usefulness of risk scores to estimate the risk of cardiovascular disease in patients with rheumatoid arthritis. Am J Cardiol. 2012;110(3):420-4.

3. Crowson CS, Rollefstad S, Kitas GD, et al. Challenges of developing a cardiovascular risk calculator for patients with rheumatoid arthritis. PLoS One. 2017;12(3):e0174656.

4. Arts EE, Popa C, Den Broeder AA, et al. Performance of four current risk algorithms in predicting cardiovascular events in patients with early rheumatoid arthritis. Ann Rheum Dis. 2015;74(4):668-74.

5. Arts EE, Popa CD, Den Broeder AA, et al. Prediction of cardiovascular risk in rheumatoid arthritis: performance of original and adapted SCORE algorithms. Ann Rheum Dis. 2016;75(4):674-80.

6. Damen JA, Hooft L, Schuit E, et al. Prediction models for cardiovascular disease risk in the general population: systematic review. BMJ. 2016;353:i2416.

7. Piepoli MF, Hoes AW, Agewall S, et al. 2016 European Guidelines on cardiovascular disease prevention in clinical practice: The Sixth Joint Task Force of the European Society of Cardiology and Other Societies on Cardiovascular Disease Prevention in Clinical Practice (constituted by representatives of 10 societies and by invited experts): developed with the special contribution of the European Association for Cardiovascular Prevention \& Rehabilitation (EACPR). Eur Heart J. 2016;37(29):2315-81.

8. Conroy RM, Pyorala K, Fitzgerald AP, et al. Estimation of ten-year risk of fatal cardiovascular disease in Europe: the SCORE project. Eur Heart J. 2003; 24(11):987-1003.

9. Cooney MT, Dudina A, De Bacquer D, et al. How much does HDL cholesterol add to risk estimation? A report from the SCORE investigators. Eur J Cardiovasc Prev Rehabil. 2009;16(3):304-14.

10. Thomsen T. HeartScore ${ }^{\oplus}$ : a new web-based approach to European cardiovascular disease risk management. London: SAGE Publications Sage; 2005.

11. Agca R, Heslinga SC, Rollefstad S, et al. EULAR recommendations for cardiovascular disease risk management in patients with rheumatoid arthritis and other forms of inflammatory joint disorders: 2015/2016 update. Ann Rheum Dis. 2017;276(1):17-28.

12. Groenewegen $\mathrm{K}$, Den Ruijter H, Pasterkamp G, et al. Vascular age to determine cardiovascular disease risk: a systematic review of its concepts, definitions, and clinical applications. Eur J Prev Cardiol. 2016;23(3):264-74.

13. Cooney MT, Vartiainen $\mathrm{E}$, Laatikainen $\mathrm{T}$, et al. Cardiovascular risk age: concepts and practicalities. Heart. 2012;98(12):941-6.

14. Cuende Jl, Cuende N, Calaveras-Lagartos J. How to calculate vascular age with the SCORE project scales: a new method of cardiovascular risk evaluation. Eur Heart J. 2010;31(19):2351-8.
15. Wibetoe $\mathrm{G}$, Ikdahl $\mathrm{E}$, Rollefstad $\mathrm{S}$, et al. Discrepancies in risk age and relative risk estimations of cardiovascular disease in patients with inflammatory joint diseases. Int J Cardiol. 2018;252:201-6.

16. Harrell FE, Lee $\mathrm{KL}$, Mark DB. Tutorial in biostatistics multivariable prognostic models: issues in developing models, evaluating assumptions and adequacy, and measuring and reducing errors. Stat Med. 1996;15:361-87.

17. Pencina MJ, D'Agostino RB. Evaluating discrimination of risk prediction models: the C statistic. Jama. 2015;314(10):1063-4.

18. Singh JA, Saag KG, Bridges SL, et al. 2015 American College of Rheumatology guideline for the treatment of rheumatoid arthritis. Arthritis Rheum. 2016;68(1):1-26.

19. Prevoo ML, van't Hof MA, Kuper HH, et al. Modified disease activity scores that include twenty-eight-joint counts. Development and validation in a prospective longitudinal study of patients with rheumatoid arthritis. Arthritis Rheum. 1995:38(1):44-8.

20. Alba AC, Agoritsas T, Walsh M, et al. Discrimination and calibration of clinical prediction models: users' guides to the medical literature. Jama. 2017;318(14):1377-84.

21. Solomon DH, Kremer J, Curtis JR, et al. Explaining the cardiovascular risk associated with rheumatoid arthritis: traditional risk factors versus markers of rheumatoid arthritis severity. Ann Rheum Dis. 2010:69(11):1920-5.

22. Ridker PM, Cushman M, Stampfer MJ, et al. Inflammation, aspirin, and the risk of cardiovascular disease in apparently healthy men. $\mathrm{N}$ Engl J Med. 1997;336(14):973-9.

23. Roubille $C$, Richer $V$, Starnino $T$, et al. The effects of tumour necrosis factor inhibitors, methotrexate, non-steroidal anti-inflammatory drugs and corticosteroids on cardiovascular events in rheumatoid arthritis, psoriasis and psoriatic arthritis: a systematic review and meta-analysis. Ann Rheum Dis. 2015;74(3):480-9.

24. Wei L, MacDonald TM, Walker BR. Taking glucocorticoids by prescription is associated with subsequent cardiovascular disease. Ann Intern Med. 2004; 141(10):764-70.

25. Westlake SL, Colebatch AN, Baird J, et al. Tumour necrosis factor antagonists and the risk of cardiovascular disease in patients with rheumatoid arthritis: a systematic literature review. Rheumatology (Oxford). 2011;50(3):518-31.

26. Westlake SL, Colebatch AN, Baird J, et al. The effect of methotrexate on cardiovascular disease in patients with rheumatoid arthritis: a systematic literature review. Rheumatology (Oxford). 2010:49(2):295-307.

27. Choi HK, Hernán MA, Seeger JD, et al. Methotrexate and mortality in patients with rheumatoid arthritis: a prospective study. Lancet. 2002; 359(9313):1173-7

28. Barnabe C, Martin BJ, Ghali WA. Systematic review and meta-analysis: antitumor necrosis factor a therapy and cardiovascular events in rheumatoid arthritis. Arthritis Care Res. 2011;63(4):522-9.

29. Crowson CS, Rollefstad S, Ikdahl E, Kitas GD, vanRiel P, Gabriel SE, Matteson EL, Kvien TK, Douglas K, Sandoo A, et al. Impact of risk factors associated with cardiovascular outcomes in patients with rheumatoid arthritis. Ann Rheum Dis. 2018;77:48-54.

30. Corrales A, Gonzalez-Juanatey C, Peiro ME, et al. Carotid ultrasound is useful for the cardiovascular risk stratification of patients with rheumatoid arthritis: results of a population-based study. Ann Rheum Dis. 2014;73(4):722-7

31. Myasoedova E, Crowson CS, Kremers HM, et al. Lipid paradox in rheumatoid arthritis: the impact of serum lipid measures and systemic inflammation on the risk of cardiovascular disease. Ann Rheum Dis. 2011;70(3):482-7.

32. Maradit-Kremers $H$, Crowson CS, Nicola PJ, et al. Increased unrecognized coronary heart disease and sudden deaths in rheumatoid arthritis: a population-based cohort study. Arthritis Rheum. 2005;52(2):402-11.

33. Pencina MJ, D'Agostino RB. Overall $C$ as a measure of discrimination in survival analysis: model specific population value and confidence interval estimation. Stat Med. 2004;23(13):2109-23.

34. van Dis I, Geleijnse JM, Boer JM, et al. Effect of including nonfatal events in cardiovascular risk estimation, illustrated with data from the Netherlands. Eur J Prev Cardiol. 2014;21(3):377-83.

35. Jørstad HT, Colkesen EB, Boekholdt SM, et al. Estimated 10-year cardiovascular mortality seriously underestimates overall cardiovascular risk. Heart. 2016;102:63-8.

36. Castaneda S, Martin-Martinez MA, Gonzalez-Juanatey C, et al. Cardiovascular morbidity and associated risk factors in Spanish patients with chronic inflammatory rheumatic diseases attending rheumatology clinics: baseline data of the CARMA Project. Semin Arthritis Rheum. 2015;44(6):618-26 
37. Wibetoe $G$, Ikdahl $E$, Rollefstad $S$, et al. Cardiovascular disease risk profiles in inflammatory joint disease entities. Arthritis Res Ther. 2017;19(1):153.

38. Jafri K, Bartels CM, Shin D, et al. Incidence and management of

cardiovascular risk factors in psoriatic arthritis and rheumatoid arthritis: a population-based study. Arthritis Care Res. 2017;69(1):51-7.

\section{Publisher's Note}

Springer Nature remains neutral with regard to jurisdictional claims in published maps and institutional affiliations.

Ready to submit your research? Choose BMC and benefit from:

- fast, convenient online submission

- thorough peer review by experienced researchers in your field

- rapid publication on acceptance

- support for research data, including large and complex data types

- gold Open Access which fosters wider collaboration and increased citations

- maximum visibility for your research: over $100 \mathrm{M}$ website views per year

At $\mathrm{BMC}$, research is always in progress.

Learn more biomedcentral.com/submissions 